\title{
A nove histidine kinase inhibitor regulating development in Bacillus subtilis
}

\author{
Ling Wang Roberto Grau, Marta Perego, and James A. Hoch ${ }^{1}$ \\ Division of Cellular Biology, Department of Molecular and Experimental Medicine, The Scripps Research Institute, \\ La Jolla, California 92037 USA
}

\begin{abstract}
Kinase $A$ is the sensor histidine kinase responsible for processing postexponential phase information and providing phosphate input to the phosphorelay that activates developmental transcription via phosphorylated Spo0A. A protein inhibitor, Kipl, of kinase A was discovered encoded in an operon of genes of unknown function but regulated by the availability of fixed nitrogen. Kipl is a potent inhibitor of the autophosphorylation reaction of kinase A but does not inhibit phosphate transfer to the SpoOF response regulator once kinase $A$ is phosphorylated. Kipl is an inhibitor of the catalytic domain of kinase $A$ affecting the ATP/ADP reactions and not the phosphotransferase functions of this domain. The inhibitory activity of Kipl is counteracted by the product of another gene in the operon, KipA. This protein may bind to Kipl, preventing its function as an inhibitor of kinase A. Kipl may be the first representative of a new class of signal transduction inhibitors that function by direct interaction with the catalytic domain of histidine kinases to counteract signals influencing the "sensor" domain of such kinases. This inhibitor represents yet another way by which the phosphorelay signal transduction system is affected by negative regulators under the control of metabolic, environmental, or cell cycle influences antithetical to the initiation of developmental transcription.
\end{abstract}

[Key Words: Phosphorelay; sporulation; histidine kinase inhibitor; signal transduction; kinase A; Bacillus subtilis]

Received June 30, 1997; revised version accepted August 5, 1997.

The initiation of developmental transcription in sporuIation of Bacillus subtilis represents a cellular commitment to a process that requires the coordination of a myriad of cellular events to assure that they occur in the correct order and at the correct time. Commitment to initiate this complex process and abandon vegetative growth and division is not made lightly and involves analysis of many signals that communicate the status of metabolism, the environment, and the cell cycle (Hoch 1993). How a cell interprets this information and how it is used to decide between vegetative growth and sporulation is only now being revealed. Many of the signals, both positive and negative, that affect this decision are interpreted through the phosphorelay signal transduction system (Burbulys et al. 1991). The phosphorelay is an extended version of the familiar two-component signal transduction systems used extensively in bacteria to perceive and transduce a variety of signals (Parkinson and Kofoid 1992). Perception is the province of a histidine kinase that acts as a signal receptor and promotes the transduction of information to chemical energy by its regulation of the autophosphorylation activity of the

${ }^{1}$ Corresponding author.

E-MAIL hoch@scripps.edu; FAX (619) 784-7966. kinase (N infa and Magasanik 1986). The kinase-bound phosphate is transferred to a response regulator protein mated specifically and usually exclusively to the kinase. Phosphorylation of the response regulator activates its functions-normally transcription regulation. The phosphorelay differs from this paradigm in that the response regulator SpoOF receives phosphate from two different kinases, KinA and KinB, and SpoOF is not a transcription factor but only an intermediate in the ultimate activation of a transcription factor (Burbulys et al. 1991; Trach and Hoch 1993). This factor, Spo0A, is the recipient of the phosphate from SpoOF by means of a response regulator phosphotransferase, $\mathrm{SpoOB}$, unique to the phosphorelay. Since originally discovered in the sporulation system of B. subtilis (Burbulys et al. 1991), phosphorelays have been described in other bacteria, yeast, and fungi (Posas et al. 1996; Uhl and Miller 1996).

Why use a multicomponent phosphorel ay in place of a two-component system when the end product, an activated transcription factor, is the same in both? The rationale originally proposed was that a multicomponent system provided more targets for regulation of the final phosphorylation level of the transcription factor (Burbulys et al. 1991). Subsequent events have shown that this is likely to be true. Regulation of the phosphorelay is now known to occur not only at the level of phosphate 
Table 1. B. subtilis strains used in this study

\begin{tabular}{|c|c|}
\hline Strain & Genotype $^{a}$ \\
\hline JH642 & wild type \\
\hline JH19980 & kinB::tet \\
\hline JH19087 & kinA::spc \\
\hline JH19108 & kinB::tet, kipA::cat ${ }^{\mathrm{b}}$ \\
\hline $\mathrm{JH} 19112$ & kinB::tet, kipl::cat ${ }^{\mathrm{b}}$ \\
\hline JH19115 & kinB::tet, amyE::pRM 111spc \\
\hline $\mathrm{JH} 19117$ & kinB::tet, kipR::cat ${ }^{\mathrm{b}}$, amyE::pRM 111spc \\
\hline JH19168 & kinB::tet, $\Delta$ kipl \\
\hline JH19190 & kinB::tet, tnrA, amyE::pRM 111spc \\
\hline JH 19192 & kinB::tet, tnrA, kipR::cat, amyE::pRM 111spc \\
\hline
\end{tabular}

${ }^{\mathrm{a} A l l}$ strains al so carry the trpC2, phe-1 markers.

bPresumed polar insertions on downstream genes in the operon.

input by control of the kinases but al so at the level of the response regulators SpoOF and SpoOA by regulated dephosphorylation (Perego and Hoch 1996b; Perego et al. 1996). Spo0A P is subject to dephosphorylation by the SpoOE phosphatase (Ohlsen et al. 1994) and SpoOF P is the substrate for two of the Rap family of phosphatases RapA and RapB (Perego et al . 1994). Because SpoOF P and SpoOA P are connected by the SpoOB phosphotransferase, which is freely reversible, dephosphorylation of one component rapidly results in lowered phosphate levels in the other.

The transcription of the genes for these phosphatases is tightly regulated by physiological processes inimical to sporulation (Perego and Hoch 1996a). RapB is induced by glucose in exponential growth, and RapA is regulated by the ComA transcription factor that induces competence, a physiological state in which sporulation is not desirable. Therefore, signals from cellular processes that are not compatible with sporulation prevent its occurrence by dephosphorylating the phosphorelay. The phosphorelay is best thought of as a signal integration circuit, in which positive signals regulating kinases and negative signals regulating phosphatases compete to influence the output of the system, the phosphorylation level of the SpoOA transcription factor (Ohlsen et al. 1994). The phosphorelay is not unlike a mitogen-activated protein (MAP) kinase cascade, where kinases and phosphatases compete in a like manner to regulate the output from the system.

A re all of the signals that influence the sporulation phosphorelay acting via known channels of phosphate ingress or egress? Have we exhausted the means by which two-component systems and phosphorelays may be regulated? The experiments described in this communication show that a new type of inhibitor of such systems can be found that acts directly on the catalytic domain of the kinase rather than on its signal perception domain. Such an inhibitor may be a paradigm for new mechanisms of signal transduction control.

\section{Results}

Cloning a kinA Inhibitory DNA fragment

$\mathrm{N}$ egative regulators of the phosphorelay (e.g., phospha- tases) that act by dephosphorylating the signal transduction components are sporulation inhibitors if overexpressed by means of placing the gene coding for them on a multicopy plasmid. This observation suggested to us that expression of a gene encoding an inhibitor of phosphate input, that is, a kinase inhibitor, should show the same phenotype when expressed from a multicopy vector. To search for such inhibitors, a library of B. subtilis chromosomal DNA in the shuttle vector pHT 315 was produced and yielded a series of sporulation-defective mutants when transformed into the sporulating B. subtilis strain JH642 (Table 1). One of these mutants carried a plasmid, pRM 90, that gave sporulation-defective transformants when purified and retransformed into the sporulation-proficient strain JH642, and the transformants were identical in phenotype to those of a kinAdefective mutant. Comparison of the sporulation frequency of strains bearing pRM 90 to the same strains carrying the parental plasmid pHT315 showed that pRM 90 reduced sporulation of the wild-type strain to the level of a kinA mutant (Table 2). PRM 90 did not further reduce the sporulation in a kinA strain, whereas when pRM90 was transformed into a kinB mutant strain (JH 19980), the transformants showed a stage 0 sporulation defect typical of a double mutant kinA, kinB strain (Table 2). These two kinases account for virtually all of the sporulation under these conditions. These results suggest that KinA was the target of pRM 90 inhibition.

When the nucleotide sequence of the chromosomal DNA fragment cloned in plasmid pRM 90 was determined, the results revealed a portion of the $B$. subtilis genome previously identified by the $B$. subtilis genome sequencing project (Fig. 1). This region is organized in an operon (see below) originally defined by six genes (see Materials and Methods) designated ycsF, ycsG, ycsl, ycs), ycsO, and ycsK (A kagawa et al. 1995).

The first gene, ycsF, encodes a protein of 257 amino acids, similar (34\% identity, 57\% similarity) to the LamB protein (262 amino acids) of Aspergillus nidulans (Richardson et al. 1992). LamB in fungi seems to be required for the utilization of lactam rings as a nitrogen source. The second gene, ycsG, codes for a highly hydrophobic protein of 404 amino acids with 11 potential transmembrane domains. This protein shows similarity

Table 2. Effect of multicopy plasmid pRM90 on sporulation

\begin{tabular}{llllc}
\hline $\begin{array}{l}\text { Strain } \\
\text { (rel evant } \\
\text { genotype) }\end{array}$ & Plasmid & $\begin{array}{c}\text { Viable } \\
\text { cells/ml }\end{array}$ & Spores/ml & $\begin{array}{c}\text { Percent } \\
\text { spores }\end{array}$ \\
\hline JH642 (wild type) & pHT315 & $2.0 \times 10^{8}$ & $3.0 \times 10^{7}$ & 15.0 \\
& pRM90 & $3.6 \times 10^{8}$ & $1.4 \times 10^{6}$ & 0.4 \\
JH19087 (kinA) & pHT315 & $3.9 \times 10^{8}$ & $2.3 \times 10^{6}$ & 0.6 \\
& pRM90 & $3.6 \times 10^{8}$ & $1.8 \times 10^{6}$ & 0.5 \\
JH19980 (kinB) & pHT315 & $3.6 \times 10^{8}$ & $5.0 \times 10^{7}$ & 14.0 \\
& pRM90 & $4.8 \times 10^{8}$ & $4.0 \times 10^{3}$ & 0.0008
\end{tabular}

aStrains carrying the multicopy plasmids were grown in $3 \mathrm{ml}$ of SSM containing erythromycin at $25 \mu \mathrm{g} / \mathrm{ml}$ for $36 \mathrm{hr}$ before plating. 


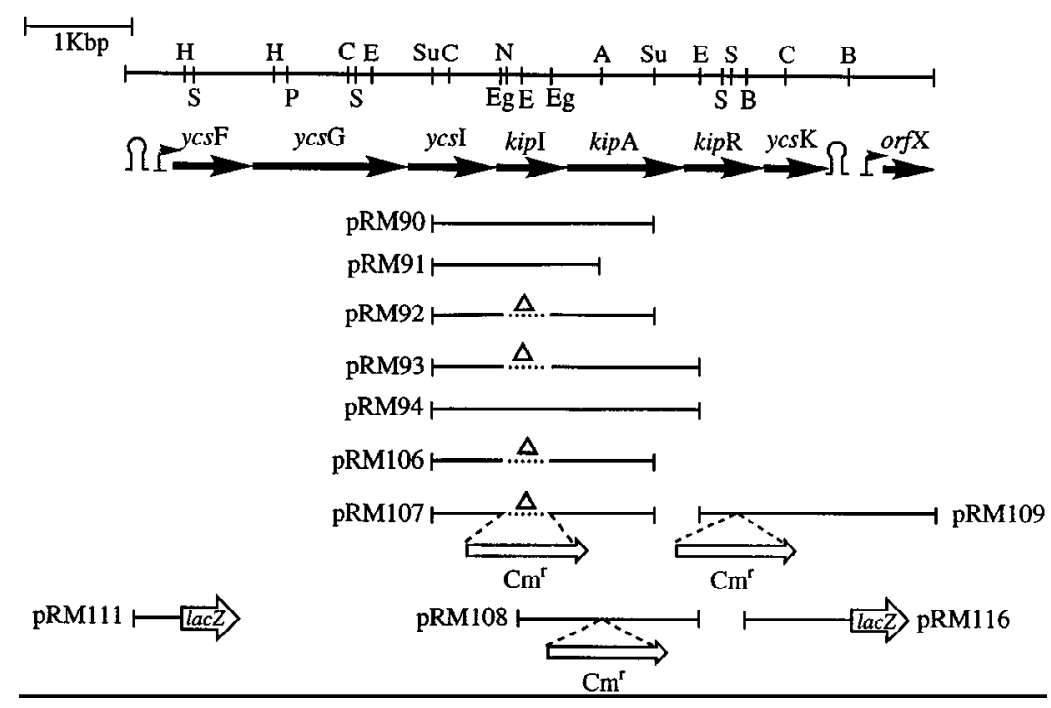

Figure 1. Restriction map of the chromosomal region carrying the operon containing the kip genes. Arrows indicate the lengths of the various genes. The position of putative promoters are indicated by small arrows. Putative transcription terminators are also shown. The fragments used in plasmid constructions are indicated by the lines. $(\Delta)$ Internal deletions. Abbreviations for restriction enzymes are (A) Apal; (B) Bbsl (not unique); (C) Clal; (E) EcoRI; (Eg) Eagl; (H) HindlII; (N) Notl; (P) PfIMI; (S) Sstl; and (Su) Sau3A (not unique).
( $21 \%$ identity, $49 \%$ similarity) to bacterial permeases such as BraB (branched chain amino acid transport system II) of Pseudomonas aeruginosa (437 amino acids) (Hoshino et al. 1990). Gene three, ycsl, encodes a product of 263 amino acids with similarity (45\% identity, $62 \%$ similarity) to a transmembrane protein of 301 amino acids from Schizosaccharomyces pombe whose function is unknown (accession no. Q09674).

Genes four and five, kipl and kipA, were designated as ycs) in the original sequencing study (Akagawa et al. 1995). Our sequencing and gene expression results indicate that ycs) is actually two genes that produce two proteins. Sequencing of this region from two wild-type Bacillus strains (see Materials and Methods) also gave two genes that expressed two proteins. The products of the kipl (240 amino acids) and kipA (337 amino acids) genes are both distantly related to the ureami dol yase enzyme of Saccharomyces cereviseae (Genbauffe and Cooper 1991), which is a single protein in yeast and is much bigger (1835 amino acids) than the sum of kipl and kipA (577 amino acids). Two genes (HI1731 and HI1730) whose products are highly similar to kipl and kipA have been identified in Haemophilus influenzae, and they are closely linked to LamB and BraB homologs (Fleischmann et al. 1995).

The sixth gene, ycsO, now renamed kipR, codes for a protein of 247 amino acids whose sequence contains a helix-turn-helix motif typical of DNA-binding proteins. Results reported below show KipR to be a regulator of the kip gene-containing operon.

The seventh gene, ycsK, codes for a protein of 213 amino acids with no significant homology to any other protein in the databank. This gene is followed by a putative transcription terminator.

\section{Gene amplification and inactivation analyses}

Plasmid pRM 90 contains the carboxyl end of the ycsl gene, the kipl gene, and a truncated kipA gene (Fig. 1). To determine the gene responsible for the sporulation phenotype, deletions were made in the plasmid. A deletion of kipl in plasmid pRM 92 (Fig. 1) was 1200-fold less effective at preventing sporulation than pRM 90 (Table 3). Deletion of a large portion of kipA in pRM 91 was without effect on sporulation inhibition. However, if a complete copy of the kipA gene was added to pRM90, the plasmid pRM94 was much less effective in preventing sporulation. Deletion of kipl from such a plasmid, pRM 93, resulted in enhanced sporulation relative to strains bearing pHT315. This enhancement is likely attributable to KipA neutralization of the chromosomally encoded Kipl. Thus, the sporulation inhibitor is encoded in kipl, and its effects are neutralized in strains bearing kipA in addition to kipl on multicopy plasmids.

Deletion of the chromosomal copy of the kipl gene with or without deletion of the kipA gene enhances sporulation (strain JH 19168; T able 4). However, deletion of kipA al one decreased sporulation 4- to 5-fold and 300fold if glucose was added to the culture medium (strain JH19108; Table 4). Data presented bel ow will show that glucose is an inducer of the kip gene-containing operon. Under glucose conditions, the kipA insertional inactivation strain JH19108 mimics a strain with a multicopy kipl. Thus, the kipl gene product is likely to be the in-

Table 3. Effect of deletions in pRM90 on sporulation of a kinB strain

\begin{tabular}{lcc}
\hline Plasmid $^{\mathrm{a}}$ & $\begin{array}{c}\text { Sporulation } \\
\text { phenotype (plates) }\end{array}$ & $\begin{array}{c}\text { Relative sporulation } \\
\text { frequency (liquid) }\end{array}$ \\
\hline pHT315 & $\mathrm{Spo}^{+}$ & 1 \\
pRM 90 & $\mathrm{Spo0}$ & 0.0008 \\
pRM 91 & $\mathrm{Spo0}$ & 0.0008 \\
pRM 92 & $\mathrm{Spo}^{+}$ & 1 \\
pRM 93 & $\mathrm{Spo}^{++}$ & 2.27 \\
pRM 94 & Spo $^{ \pm}$ & 0.56 \\
\hline
\end{tabular}

aparental strain for all plasmids was JH19980 kinB::tet. 
Wanget al.

Table 4. Effect of kipl and kipA chromosomal genotype and glucose on sporulation

\begin{tabular}{|c|c|c|c|c|c|c|c|c|}
\hline \multirow[b]{2}{*}{ Strain } & \multicolumn{2}{|c|}{ Relevant genotype } & \multicolumn{2}{|c|}{-Glucose } & \multirow{2}{*}{$\begin{array}{c}\text { Percent } \\
\text { spores }\end{array}$} & \multicolumn{2}{|c|}{ +Glucose } & \multirow{2}{*}{$\begin{array}{c}\text { Percent } \\
\text { spores }\end{array}$} \\
\hline & kipl & kipA & viable cells/ml & spores/ml & & viable cells/ml & spores/ml & \\
\hline JH19980 & + & + & $4.9 \times 10^{8}$ & $1.2 \times 10^{8}$ & 24.5 & $1.6 \times 10^{9}$ & $9.8 \times 10^{5}$ & 0.06 \\
\hline JH19108 & + & - & $4.6 \times 10^{8}$ & $2.4 \times 10^{7}$ & 5.2 & $2.2 \times 10^{9}$ & $5.0 \times 10^{3}$ & 0.0002 \\
\hline $\mathrm{JH} 19112$ & - & - & $4.5 \times 10^{8}$ & $1.6 \times 10^{8}$ & 35.5 & $1.4 \times 10^{9}$ & $1.2 \times 10^{6}$ & 0.08 \\
\hline $\mathrm{JH} 19168$ & - & + & $4.9 \times 10^{8}$ & $1.9 \times 10^{8}$ & 38.8 & $1.6 \times 10^{9}$ & $2.8 \times 10^{6}$ & 0.17 \\
\hline
\end{tabular}

Cultures were grown in SSM at $37^{\circ} \mathrm{C}$ with or without glucose at $2 \%$ (wt/vol) final concentration. Samples were tested for spore formation after $\sim 16 \mathrm{hr}$ of growth. Results are the average of two independent experiments.

hibitor of sporulation, and the genetics are consistent with the product of the kipA gene product being an inhibitor of Kipl or at least preventing or reversing the sporulation inhibition by Kipl. N ote that the insertional inactivation strains JH19108 and JH 19112 may also prevent expression of the kipR regulator gene (described below), but this regulator has little effect in the nitrogenrich medium used in the experiments described in Table 4. Compare strains JH 19112 and JH 19168 where the latter strain has a nonpolar deletion of kipl and the results are the same. To test whether kipl was a direct inhibitor of KinA, the Kipl and KipA proteins were purified and tested for their effects on the phosphorelay reactions.

\section{Effect of Kipl and KipA on KinA autophosphorylation}

The kipl gene and a complete copy of the kipA gene were amplified by PCR from chromosomal DNA and subcloned independently into the pET vector expression system with His-tagged extensions. After the sequence of the genes was verified, each protein was expressed in Escherichia coli and purified by Ni-NTA affinity chromatography. Kipl was obtained as a soluble protein in this system, whereas KipA was only partially sol uble and mostly present in inclusi on bodies. The purified proteins gave the expected molecular masses when analyzed by SDS-PAGE: Kipl was 26,720 daltons, and KipA was 36,931 daltons.

The effect of the proteins on KinA activity was analyzed in the standard phosphorylation reaction with [ $\gamma^{-}{ }^{32}$ P]ATP (Fig. 2A). Kipl at $4 \mu \mathrm{m}$ concentration strongly inhibited the autophosphorylation of $0.5 \mu \mathrm{M} \mathrm{KinA}$. The addition of $6 \mu \mathrm{M} \mathrm{KipA}$ to this reaction partially overcame the inhibition by Kipl. When $2 \mu \mathrm{M}$ SpoOF was added to the reaction al ong with KinA, both SpoOF and KinA were labeled. However, when added, Kipl strongly inhibited the accumulation of SpoOF P and no labeled KinA was observed. The addition of KipA alone to the autophosphorylation of KinA or to the phosphorylation of SpoOF had no effect. However, KipA addition partially reversed the inhibition by Kipl of SpoOF P accumulation. These results suggested that Kipl inhibits the autophosphorylation of KinA and this inhibition may be partially prevented by KipA. These data are entirely consistent with the in vivo genetic data.

To gain some insight into the site of action of Kipl, a kinase domain fragment of KinA consisting of the last
217 carboxy-terminal residues (L. Wang and J.A. Hoch, in prep.), was tested for inhibition by Kipl. The kinase A catalytic domain is deficient in autophosphorylation, but the residual activity in the truncated protein is inhibited by Kipl (Fig. 2B). Therefore, the site of KinA inhibition by Kipl is the catalytic domain. The inhibition of SpoOF P accumulation by Kipl may be only related to the effect of Kipl on the autophosphorylation of KinA, but the present data do not exclude an effect on the phosphotransferase reaction. Titration of Kipl against $0.5 \mu \mathrm{M}$ KinA showed half-maximal inhibition at 1-2 $\mu \mathrm{m}$ Kipl (Fig. 3). The inhibition is noncompetitive with respect to ATP (data not shown).

\section{Kipl does not inhibit NRII kinase of E. coli}

To determine whether Kipl was specific for KinA or whether it was a general kinase inhibitor, the effect of Kipl was tested on purified N RII kinase of E. coli. Kipl at a concentration sufficient to inhibit the autophosphorylation of KinA was without effect on the autophosphorylation of NRII. Titration of Kipl against NRII at a higher concentration had no effect on the N RII reaction (Fig. 4).
A

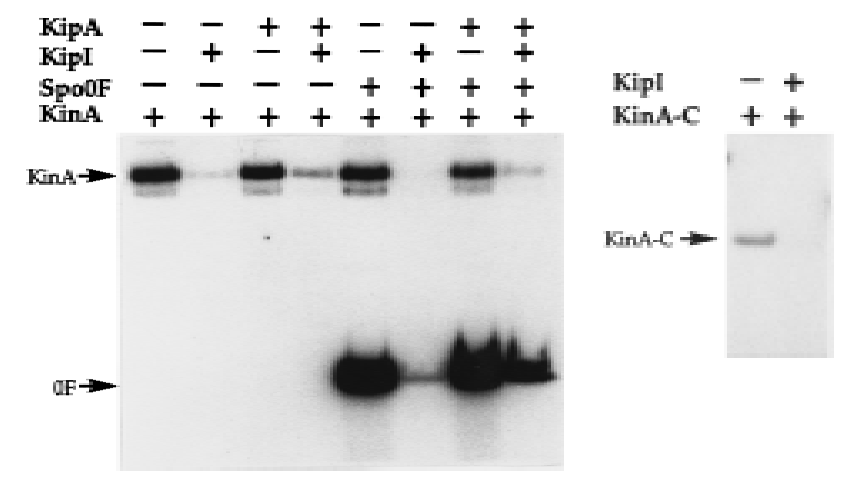

Figure 2. Effect of Kipl and KipA on KinA and KinA-C autophosphorylation. Reactions were performed as described in $\mathrm{Ma}$ terials and Methods. KinA (A) and KinA-C (B) were used at 0.5 $\mu \mathrm{M}$ while SpoOF, Kipl, and KipA were added at final concentrations of 2,4 , and $6 \mu \mathrm{m}$, respectively. (+) The proteins present in each reaction. 


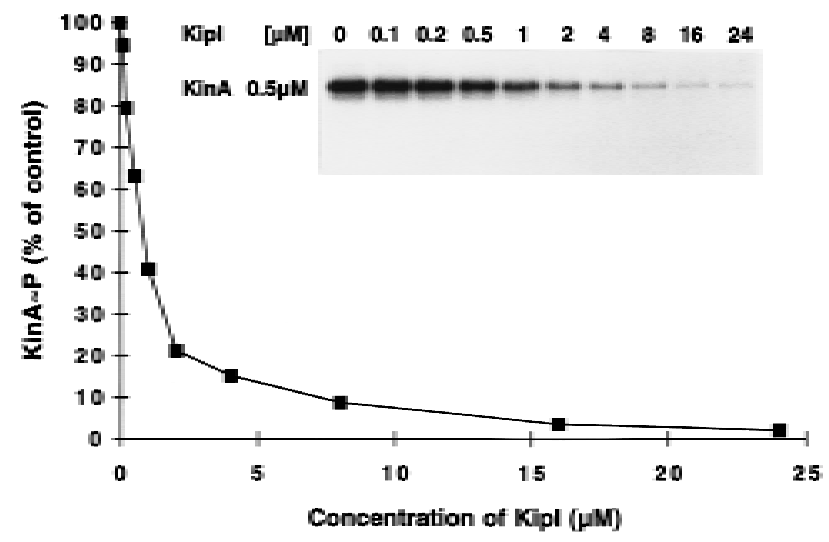

Figure 3. Titration of inhibition of KinA autophosphorylation by Kipl. The assay was performed in standard conditions as described in Materials and M ethods. Kipl was added at increasing concentrations, as shown. The reactions were loaded on a $15 \%$ SDS-polyacrylamide gel, which was exposed to X-ray film and subjected to quantitative anal ysis by a M olecular Dynamics Phosphorlmager. The percentage of Iabeled KinA compared to the labeled KinA obtained in the control in the absence of Kipl was plotted against the concentrations of Kipl used in each reaction.

\section{Effect of Kipl on reverse reactions of KinA}

It seemed possible that Kipl could have an apparent effect on the autophosphorylation of KinA either by inhibiting this reaction or by being a direct phosphatase of KinA P. To decide between these possibilities, labeled KinA P was produced and purified from residual ATP. When KinA P was incubated with ADP, some loss of labeled KinA P was observed (Fig. $5 A$, lane 2) and this can all be accounted for by conversion to ATP (Fig. 5B). $\mathrm{N}$ o free phosphate was formed. Addition of Kipl prevents this loss of KinA P and inhibits formation of ATP (Fig. $5 A, B$, lane 3). No free phosphate was observed. Addition of KipA alone or with Kipl has little apparent effect (Fig. $5 \mathrm{~A}, \mathrm{~B}$, lanes 4,5). Rather than stimulate the loss of KinA $\sim P$ through a phosphatase reaction, the addition of Kipl prevented the ADP-dependent loss of KinA P. Therefore, Kipl inhibits both the ATP-dependent auto-

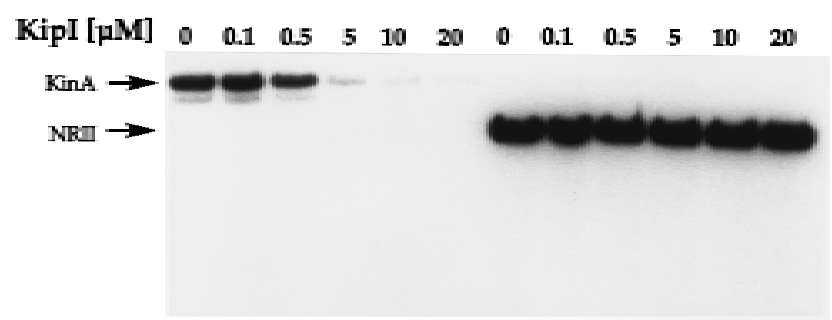

Figure 4. Specificity of Kipl inhibition toward KinA. Autophosphorylation conditions were as described in $M$ aterials and Methods. KinA and NRII were used at $0.5 \mu \mathrm{m}$ final concentration. Increasing concentrations of Kipl resulted in inhibition of KinA autophosphorylation, but no effect was observed on N RII.

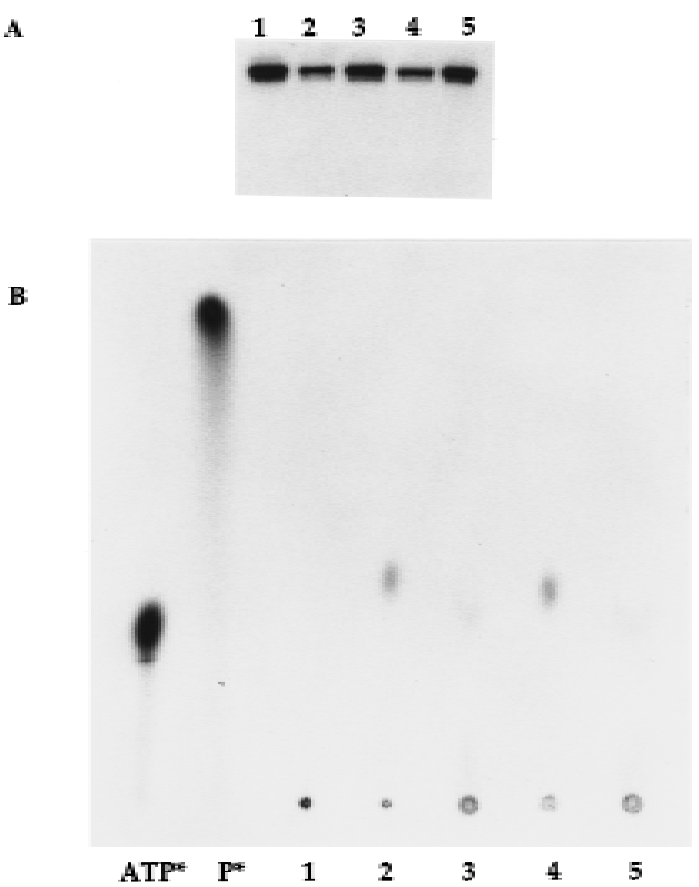

Figure 5. Mechanism of Kipl inhibition of KinA autophosphorylation. Purified KinA P (30 pmoles) was incubated in the standard reaction buffer for $3 \mathrm{~min}$ at room temperature in the presence of nothing (lane 1); $300 \mu \mathrm{M}$ ADP (lane 2); $300 \mu \mathrm{M}$ ADP and $5 \mu \mathrm{M}$ Kipl (lane 3); $300 \mu \mathrm{M}$ ADP and $5 \mu \mathrm{M}$ KipA (lane 4); 300 $\mu \mathrm{M} A \mathrm{AD}$ and $5 \mu \mathrm{m}$ each Kipl and KipA (lane 5). Final volume was $30 \mu \mathrm{l}$. Reactions were stopped by the addition of $10 \mu \mathrm{l}$ of $5 \times$ SDS loading buffer. Reaction mixtures (39 $\mu \mathrm{l})$ were loaded on a $15 \%$ SDS-polyacrylamide gel (A) while $1 \mu$ l was applied to a TLC plate (B). M arkers used were purified $\left[\gamma^{-32}\right.$ P]ATP (ATP*) and ${ }^{32} \mathrm{P}$ carrier-free (Amersham) (P*).

phosphorylation and its reverse reaction from ADP. Thin-layer chromatography (TLC) of several other reactions reveal ed that the $\left[\gamma^{-32}\right.$ P]ATP was not hydrolyzed by Kipl, and the addition of KinA to Kipl did not stimulate ATP hydrolysis (data not shown). The results are consistent with Kipl being a specific inhibitor of KinA and its effect does not reside in an activity that destroys ATP or dephosphorylates KinA P.

\section{Effect of Kipl on phosphotransferase reactions}

To determine whether Kipl affected the phosphotransferase reaction of KinA, labeled KinA P and SpoOF P were prepared and purified. Purified KinA P incubated with Kipl is not dephosphorylated, and addition of SpoOF results in uninhibited transfer of phosphate to SpoOF (Fig. 6A). The same results were obtained with purified labeled KinA-C $\sim$, which consists of only the catalytic domain of KinA (Fig. 6A). When purified SpoOF P was incubated with Kipl, there was no loss of phosphate from SpoOF P , and the back reaction to KinA was uninhibited (Fig. 6B). The identical results were obtained with KinA-C as the phosphate acceptor (Fig. 6B). 
Wang et al.
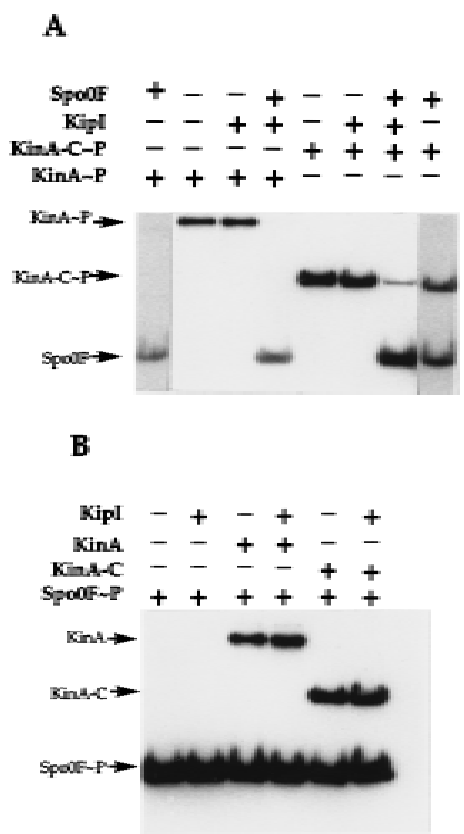

Figure 6. Kipl does not prevent the phosphotransferase reaction from KinA/KinA-C $\sim \mathrm{P}$ to SpoOF and from SpoOF P to KinA/ KinA-C. (A) Purified KinA P or KinA-C $\sim P$ (30 pmoles) was incubated for $3 \mathrm{~min}$ at room temperature in standard reaction buffer. The presence of SpoOF $(5 \mu \mathrm{M})$ and/or Kipl $(5 \mu \mathrm{M})$ in the reaction is indicated (+). (B) SpoOF P (50 pmoles) was incubated in standard reaction buffer with KinA $(5 \mu \mathrm{M})$ or KinA-C $(5 \mu \mathrm{M})$ in the presence of Kipl $(5 \mu \mathrm{M})$ as indicated (+).

Therefore, Kipl affects the KinA autophosphorylation reaction and its reverse reaction. It is not an inhibitor of the reverse phosphotransferase reaction and likely does not inhibit the forward reaction. It is not a phosphatase of KinA P or of SpoOF P and does not stimulate a latent autophosphatase activity of KinA.

\section{Catabolite induction of kip genes}

Transcriptional analysis of the kip gene-containing operon was carried out by assaying $\beta$-galactosidase activity of a promoter-lacZ fusion construction (pRM 111; Fig. 1) cloned in the transcriptional fusion vector pJM 116 and integrated ectopically in the amyE locus (see Materials and Methods). In the nutrient broth-based Schaeffer's sporulation medium (SSM), kip transcription increased during the logarithmic phase, reaching a maximum level at $\mathrm{T}_{0}$ (15 Miller units), thereafter decreasing to $\sim 7 \mathrm{M}$ iller units between $T_{3}$ and $T_{4}$ (Fig. 7). Because the sporulation defect of a kipA deletion strain was enhanced by the addition of glucose, transcription of the operon was anaIyzed in the presence of sugars. The addition of gl ucose at $1 \%$ final concentration to SSM strongly induced transcription of the operon in early exponential phase, but a sharp decrease reproducibly occurred at $\mathrm{T}_{-1}$ (Fig. 7). Si miIar induction was al so observed when fructose at $1 \%$ or glycerol at $2 \%$ was added to SSM. The same construction was also placed isotopically on the chromosome by means of a pJM 783 integrative plasmid, and the same patterns of transcription were observed.

The induction of the operon by glucose provided a means to determine the boundaries of the operon. Transcriptional lacZ fusions to kipl, kipR, and ycsK were constructed in pJM 783 and isotopically integrated in the B. subtilis chromosome as described in Materials and Methods. $\beta$-Galactosidase assays were carried out in SSM in the presence of $1 \%$ glucose. These lacZ fusions showed the same pattern of induction observed with plasmid pRM 111, although the maximum level of transcription gradually decreased the farther the distance from the promoter (data not shown). No transcriptional activity was obtained from plasmid pRM 116 carrying a lacZ fusion to the $3^{\prime}$ end of a putative Rho-independent terminator of transcription, located downstream of ycsK (Fig. 1). Furthermore, transcription of ycsL, located downstream of theterminator, showed a totally different regulatory pattern (data not shown). This analysis suggests that the operon contai ning the kip genes comprises seven cistrons in a single transcriptional unit induced by several carbon sources.

\section{Nitrogen control of kip gene expression}

When the B. subtilis strain JH19115 carrying the promoter-lacZ fusion construct PRM 111 was grown in SSM

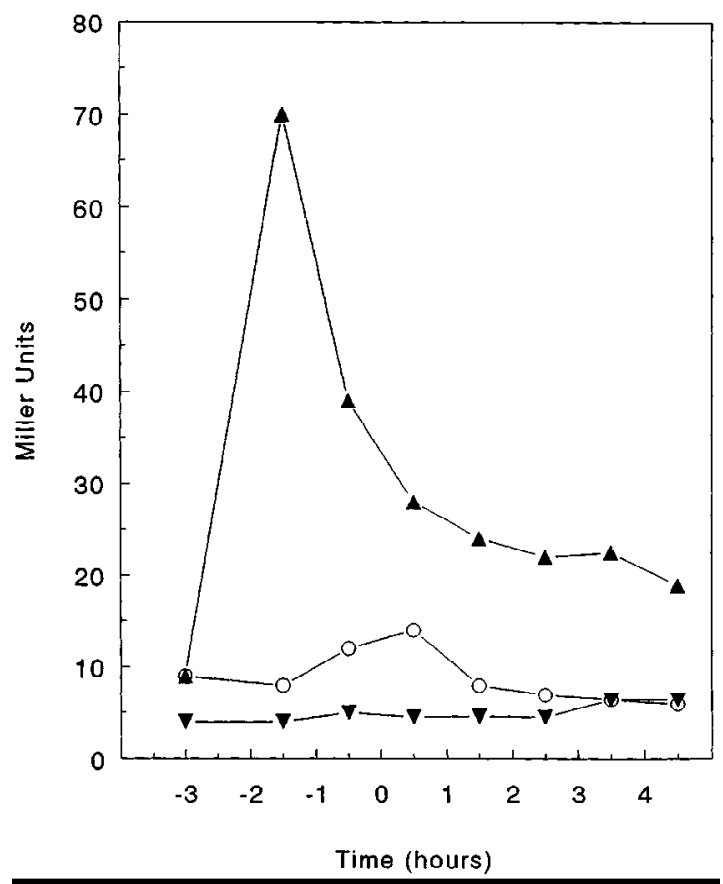

Figure 7. Expression of the operon containing the kip genes in sporulation medium. The wild-type strain JH19115 harboring the lacZ fusion construct plasmid pRM 111 was grown in SSM $(\bigcirc)$, in SSM supplemented with $1 \%$ glucose $(\mathbf{A})$, and in SSM supplemented with $1 \%$ glucose and $0.3 \%$ glutamine $(\boldsymbol{\nabla})$. Time 0 represents the transition from vegetative to sporulation phase. $\beta-G a l a c t o s i d a s e$ was expressed as Miller units (Miller 1972). 
in the presence of $0.3 \%$ gl utamine, induction by glucose was prevented (Fig. 7). Strain JH 19115 was grown in Spizizen salts minimal medium in the presence of different nitrogen sources to examine the basis for this nitrogen effect. In a good nitrogen source, such as $\mathrm{N} \mathrm{H}_{4}{ }^{+}$, very little transcription was observed. However, poor nitrogen sources such as allantoin, allowed higher levels of transcription from the promoter-lacZ construct pRM 111 . Expression in different nitrogen sources increased as follows: $\quad \mathrm{NH}_{4}{ }^{+}<$arginine $<$glutamine $<$urea $<$proline $=\gamma$ amino butyric acid = asparagine <allantoin < gl utamate (data not shown). When a good and a poor nitrogen source were both present in the medium, the good nitrogen source effect was dominant.

$\mathrm{M}$ any nitrogen-regulated genes in B. subtilis are transcriptionally activated by the TnrA regulator, which responds to poor nitrogen conditions (Wray et al . 1996). We tested whether the enhanced transcription of the kip gene-containing operon under these conditions was a result of TnrA action by studying transcription in a tnrA deletion strain. Cells were grown in minimal glucose media with glutamate as a nitrogen source, and $\beta$-galactosidase activity driven by a single-copy chromosomal promoter-lacZ construct (pRM 111) was assayed. Deletion of kipR increased the final level of transcription $>10$-fold (Fig. 8). Deleting tnrA in this kipR mutant pre-

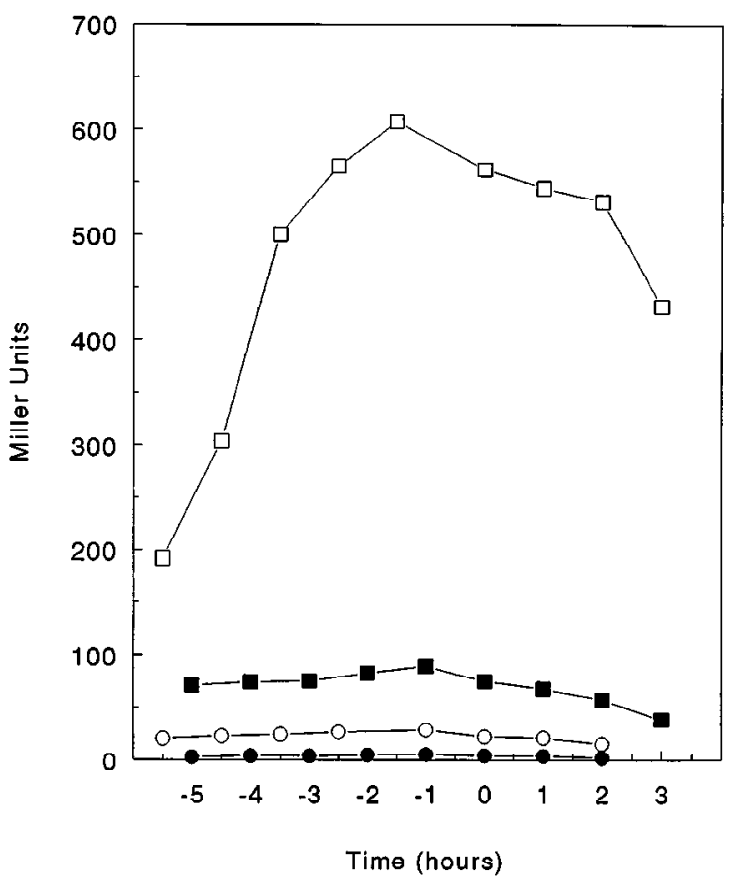

Figure 8. Regulation of expression by KipR and TnrA. $\beta$-Galactosidase activity of the lacZ fusion construct carried by plasmid pRM 111 was assayed in the wild-type strain JH19115 (O), the kipR mutant JH19117 ( $\square$ ), in the tnrA mutant JH19190 (0), and in the kipR, tnrA double mutant JH19192 (ם). Cells were grown in Spizizen salts minimal medium supplemented with glutamate, as described in Materials and Methods. Time and units as in Fig. 7. vented most of this increase, indicating that TnrA is an activator of kip operon transcription and the loss of repression regulation by KipR allows TnrA to activate transcription of the operon. In the absence of T nrA, KipR repression of kip transcription is essentially complete.

\section{Discussion}

The regulation of the activity of KinA is of paramount importance for the initiation of developmental transcription at the onset of sporulation. KinA is functional at the end of exponential growth and must respond to those cellular signals that would promote sporulation at the expense of further growth. Essentially all of the phosphate that is sequestered by the phosphorelay components at this time arises from the action of KinA. Many of the mechanisms by which KinA is regulated still remain obscure, although the proteins described here must play a role in controlling KinA activity under some physiological conditions. The operon in which Kipl and KipA reside is induced by gl ucose when readily available sources of nitrogen, such as glutamine or ammonia, are scarce. This operon is regulated by TnrA activation and by KipR repression. TnrA positively regulates a number of genes and operons coding for proteins that degrade nitrogen-containing compounds (Ferson et al. 1996; Wray et al. 1996). TnrA-dependent promoters are characterized by a common upstream sequence (TGTNAN 7 TNACA), two of which are present in the promoter for the kip gene-containing operon, from the putative -60 to -30 region. Nitrogen-limited TnrA activation is clearly antagonized by KipR repression, which responds to some other function of the operon. In addition, there is some induction by catabolites that has an unknown basis. It seems likely that the genes of this operon must code for a system to take up and degrade some nitrogenous compound, perhaps with a lactam ring, but its identity is obscure. Regardless, some physiological situations responsible for induction must be contrary to sporulation, as the product of induction, Kipl, is a potent inhibitor of KinA activity.

Kipl is an inhibitor of the autophosphorylation of KinA by ATP. It is also an inhibitor of the reverse reaction from KinA P to KinA and ATP. Kipl does not inhibit by dephosphorylating the substrate or the product. Inhibition is not attributable to stimulation of a phosphatase activity of the kinase similar to that of the action of PII on NRII of nitrogen regulation ( $\mathrm{N}$ infa et al. 1995). It also does not stimulate the reverse reaction, giving an apparent inhibition. Kipl targets the carboxyterminal catalytic domain where it interferes with the ATP-dependent reactions of the kinase. However, the inhibition is noncompetitive with respect to ATP. Because Kipl is an inhibitor of the autophosphorylation of the isolated catalytic domain of KinA, its activity does not depend on the amino-terminal "sensor" domain of this kinase. Whether the amino-terminal domain of this kinase plays any role in the binding of Kipl cannot be determined. A detailed kinetic comparison of the effects of Kipl on intact and amino-terminal truncated KinA 
would be fruitless, as all amino-terminal truncated versions of KinA are defective in the autophosphorylation reaction (L. Wang and J.A. Hoch, unpubl.). It seems most likely that the sensor domain recognizes something other than $\mathrm{Kipl}$ and acts to regulate the kinase in response to other signals.

In contrast to its effects on the autophosphorylation reaction, Kipl appears to have little effect on the phosphotransferase reaction of KinA. Purified KinA P transfers its phosphate to SpoOF unimpeded by Kipl. SimiIarly, purified SpoOF P transfers phosphate back to KinA or to an amino-terminal truncated KinA regardless of the presence of Kipl. Thus, Kipl does not interfere with the capacity of the kinase to recognize its cognate response regulator or to transfer phosphate on and off the reactive histidine of KinA. This suggests that the structure of the catalytic domain is such that the autophosphorylation and response regulator recognition portions of the molecule are independent and are not integrated or overlapping.

Genetic studies indicated that KipA modulated the inhibitory activity of Kipl on sporulation. Overexpression of Kipl inhibited sporulation, whereas overexpression of KipA enhanced sporulation and a strain producing both proteins from a plasmid was only slightly sporulation defective. KipA produced from the expression vector in E. coli was only partially effective in reversing the Kipl effects in vitro. This discrepancy between in vivo and in vitro results is likely to be a result of expressing KipA in E. coli, where it is mainly present in inclusion bodies. Although KipA was purified from the soluble fraction, it seems likely that most of this protein is not in a native conformation and does not have native activities. Both Kipl and KipA have been produced in the same cell from an expression vector (L. Wang, R. Grau, M. Perego, and J.A. Hoch, unpubl.). In this case, a His-tagged Kipl and KipA copurified on a Ni-NTA column, indicating that Kipl and KipA may form a complex. Regardless of whether these data explain the activity of KipA on Kipl inhibition in vitro, the genetic evidence that KipA counteracts Kipl inhibition is compelling.

What the interaction of Kipl with both KinA and KipA has to do with the actual role of Kipl in vivo is still a mystery. Kipl and KipA were identified in the B. subtilis sequencing project as homologous to ureamidolyase of $\mathrm{S}$. cereviseae (Akagawa et al. 1995). Homologs of Kipl and KipA were also found in the $\mathrm{H}$. influenzae genome and identified with the yeast enzyme (Fleischmann et al. 1995). U reamidolyase catal yzes the ATP-dependent degradation of urea to $\mathrm{NH}_{3}$ and $\mathrm{CO}_{2}$ via allophanic acid (Whitney and Cooper 1973). The available evidence is not in agreement with Kipl and KipA being a bacterial form of ureamidolyase. N either Kipl nor KipA is biotinylated whether assayed in B. subtilis or when expressed in $\mathrm{E}$. coli. No ureamidolyase activity can be detected in purified Kipl and KipA. A urease-defective mutant of B. subtilis cannot be made to use urea as a nitrogen source even if the operon bearing Kipl and KipA is induced. These unpublished experiments are not consistent with a urea-degrading role for Kipl and KipA. The function of the operon encoding Kipl and KipA is obscure, but the operon is regulated by available nitrogen in a manner very similar to that of ureamidolyase in S. cereviseae (Magasanik 1992; Cunnigham et al. 1994).

Kipl acts as an anti-kinase and KipA could be thought of as an anti-anti-kinase. Because kipl and kipA are transcriptionally coregulated, it seems unlikely that expression controls determine the activity of the anti-kinase. It is reasonable to assume that Kipl-KipA interaction regulates anti-kinase activity, and this interaction may be subject to effector molecules and/or covalent modification.

It is generally believed that the catalytic domain of histidine kinases is controlled by the sensor domain, which acts as the information recognition and processing site. To our knowledge, Kipl is the first inhibitor of two-component histidine kinases directed toward the catalytic domain. The effects of Kipl on KinA suggest that the catalytic domain may not be entirely passive in signal transduction. Inhibitors of the catalytic domain may act to block or counteract signals that influence the sensor domain. Perhaps two-component systems designed to recognize the cellular level of a single metabolite such as available nitrogen may only need a sensor domain to interact with a single effector. The phosphorelay is a signal integration circuit that regulates a cellular developmental event, and many signals can and do influence the decision to initiate development. The cell has evolved several mechanisms to cope with these signals other than regulation of the sensor domain. Some signals manifest in the activation of phosphatases that dephosphorylate the response regulator components of the phosphorelay (Perego et al . 1994). The signals transduced by phosphatases are believed to be negative influences on the developmental process that function by counteracting phosphate input into the phosphorelay by KinA (Ohlsen et al. 1994). Because phosphatases play this role, it should not be surprising that the cell would use inhibitors such as Kipl to counteract phosphate input by KinA.

The rational e for a cell using the phosphorel ay to control development has been postulated to stem from the potential of this type of signal transduction system for regulation by a variety of signals promoting either growth or sporulation (Burbulys et al. 1991). Because sporulation initiation is seemingly only dependant on raising the level of phosphorylation of the Spo0A transcription factor, inhibition by phosphatases or enzyme inhibitors should prevent the process. It should not be unexpected that other components of the phosphorelay are regulated by dephosphorylation or inhibition of function.

\section{Materials and methods}

Bacterial strains and growth conditions

The $B$. subtilis strains used in this study are described in Table I [the tnrA deletion strain SF706T was obtained from Susan Fisher (Ferson et al. 1996)]. For sporulation efficiency, B. subtilis strains were grown in Schaeffer's sporulation medium (Schaef- 
fer et al. 1965) and then treated with $\mathrm{CHCl}_{3}$ or heated at $80^{\circ} \mathrm{C}$ for $10 \mathrm{~min}$ before plating. Transformation of $\mathrm{B}$. subtilis was carried out as described (Anagnostopoulos and Spizizen 1961).

$\beta$-Galactosidase in B. subtilis strains harboring lacZ fusions were assayed as described previously, and the specific activity was expressed in Miller units (M iller 1972). Cells were grown in Schaeffer's sporulation medium or Spizizen's minimal medium (Spizizen 1958) without $\left(\mathrm{N} \mathrm{H}_{4}\right)_{2} \mathrm{SO}_{4}$ and supplemented with 20 $\mathrm{mm} \mathrm{MgSO}_{4}, 1 \%$ glucose, $0.005 \%$ each tryptophan and phenylalanine, and $20 \mathrm{~mm}$ nitrogen source.

\section{Plasmids and strains constructions}

Plasmid pRM 90 was obtained from a B. subtilis JH 642 chromosomal library constructed by ligating partial Sau3A restriction fragments in the multiple cloning site of the pHT315 shuttle vector (Arantes and Lereclus 1991; V. Dartois, T. Djavakhishvili, and J.A. Hoch, unpubl.). Plasmid pRM 91 was derived from pRM 90 by deletion of the fragment comprised of the A pal site in kipA and the EcoRI site in the multiple cloning site. Plasmid pRM 92 was obtained by religating plasmid pRM 90 digested previously with Eagl to create a 500-bp internal deletion in the Kipl coding gene. The multicopy vector pRM 94 carrying both kipl and kipA coding sequences was obtained by replacing the Apal-EcoRI fragment of pRM90 with a Apal-EcoRI fragment containing the entire kipA gene obtained by PCR amplification of chromosomal DNA. The kipA multicopy plasmid pRM 93 was obtained by digestion of pRM 94 with Eagl and religation to delete the Eagl fragment internal to kipl.

The entire operon containing the kip genes and its boundaries were amplified by PCR using the Expand High Fidelity PCR system (Boehringer Mannheim) from chromosomal DNA of strain JH642 with the ol igonucl eotides 5'-AGACATGGTACCAGGAAACGGCTGATTATATCACG-3' Kpnl and 5'-AAATATCTGCAGCTTGTGGAGTGGGAAACACTTG-3' Pstl. The fragment obtained (6908 bp) was digested with Kpnl, EcoRI, and Pstl to generate four fragments of $2,1.45,1.6$, and $1.8 \mathrm{kbp}$, respectively. Each fragment was cloned in the shuttle vector pHT 315 (Arantes and Lereclus 1991) to generate plasmids that were subjected to partial nucleotide sequence.

Plasmids pRM 107, pRM 108, and pRM 109 were constructed in the integrative vector pJ M 103 (Perego 1993). Their linearization and transformation in $\mathrm{B}$. subtilis-competent cells resulted in integration by a double crossover event that yielded strains JH19112, JH 19108, and JH19117, respectively. In these strains, all of the genes in the operon located downstream of the site of integration may also be inactivated because of a polar effect.

For the construction of strain JH19168 (kipl-kipA ${ }^{+}$), plasmid pRM 106, constructed in the integrative vector pJ M 103, was integrated in the chromosome of $\mathrm{JH} 19980$ via single crossing-over by transformation and sel ection for $\mathrm{Cm}$ resistance $\left(\mathrm{Cm}^{\mathrm{R}}\right)(5 \mu \mathrm{g} /$ $\mathrm{ml})$. Two $\mathrm{Spo}^{+}$transformants were grown for several days in Luria Bertani (LB) medium without antibiotic to allow spontaneous excision of the plasmid from the chromosome. The cultures were grown to stationary phase and then diluted 1:100 in fresh medium every $12 \mathrm{hr}$ for 5 days before plating serial dilutions on LB agar plates. The colonies obtained were screened for $\mathrm{Cm}$ sensitivity $\left(\mathrm{Cm}^{\mathrm{S}}\right)$. Three colonies out of 200 checked were $\mathrm{Cm}^{\mathrm{s}}$. Their chromosomal DNA was used in PCR reactions using oligonucleotides 5'-TGAGAATCATGACTGTACGATATCAAATCGAAC-3' and 5'-TCCCGTCTCGAGTGTCAGCCATTCCATCTTCATTCTCGTTTTCA $\overline{G T T C-3^{\prime}}$ to amplify the kipl region and verify the presence of the internal deletion of $\sim 0.6 \mathrm{~kb}$. The three $\mathrm{Cm}^{\mathrm{s}}$ colonies analyzed yiel ded a PCR product $0.6 \mathrm{~kb}$ smaller than the control chromosomal DNA from
$\mathrm{JH}$ 19980, $\left(\mathrm{kipl}^{+}, \mathrm{kipA}^{+}\right)$. One of these $\mathrm{Cm}^{\mathrm{S}}$ colonies was designated JH19168 and used in further studies.

Transcriptional lacZ fusion plasmids were constructed in vectors pJM 783 for isotopic integrations and pJM 116 for ectopic integrations in the amyE locus (Perego 1993). Plasmid pRM 111 was constructed by cloning a PCR-generated Kpnl-HindlII fragment into pJM 116. Plasmid pRM 112 carries the same fragment but in the lacZ fusion vector pJM 783.

\section{Nucleotide sequence}

Extensive nucleotide sequence of the operon containing the kip genes was carried out to define the precise end points of each open reading frame. The regions comprising nucleotides 73009060 and 10350-13000 in the original sequence (GenBank accession no. d38161) were resequenced from fragments obtained by PCR amplification of the chromosomal DNA of strain JH642. Corrections have been submitted to the databank as an update to the original sequence. To ensure that kipl and kipA were two separate genes, the chromosomal region containing both genes was amplified by PCR reaction from chromosomal DNA extracted from two natural Bacillus isolates (Bacillus natto from a commercial $\mathrm{N}$ atto and $\mathrm{B}$. subtilis polish, a strain in our collection). The fragments were cloned in the pET 16b expression vector, sequenced, and then transferred to the $\mathrm{E}$. coli BL21 (DE3) strain for protein expression and purification. The results (not shown) confirmed that in these Bacillus natural isolates, Kipl and KipA are two distinct proteins coded by two separate genes.

\section{Expression and purification of Kipl and KipA}

The coding sequences for kipl and kipA were amplified by PCR reaction from chromosomal DN A of the wild-type strain JH642. kipl was cloned as a Ncol-Xhol fragment in the N col-Xhol sites of the pET 28a expression vector (N ovagen), which promotes the fusion of the carboxy-terminal end of the protein with six histidine residues. The kipA gene was cloned in the $\mathrm{Ndel}$-BamHI sites of the pET 16b vector (N ovagen), thereby adding 10 histidine codons to the $5^{\prime}$ end of the gene. Plasmids were constructed in E. coli DH $5 \alpha$ and, after sequence verification, transferred in the E. coli expression host BL21(DE3) plysS. Cells carrying the pET28a-Kipl or the pET16b-KipA expression vectors were grown in LB medium supplemented with kanamycin $(30 \mu \mathrm{g} / \mathrm{ml})$ or ampicillin $(100 \mu \mathrm{g} / \mathrm{ml})$, respectively. At an $O D_{600}$ of 0.6 , cells were induced by the addition of $1 \mathrm{~mm}$ IPT G and al lowed to grow for an additional $3 \mathrm{hr}$ at $37^{\circ} \mathrm{C}$ before harvesting. The His-tagged proteins were purified by affinity chromatography on $\mathrm{Ni}$-NTA agarose columns (Qiagen), in $20 \mathrm{~mm}$ Tris (pH 8.0), $10 \mathrm{mM} \mathrm{KCl}$, and $1 \mathrm{~mm}$ PMSF using a $0-150 \mathrm{~mm}$ gradient of imidazole.

\section{Phosphorylation assay conditions}

Phosphorylation assays were performed in $30 \mu \mathrm{l}$ volume in the standard reaction buffer (50 mM EPPS at pH 8.0, 0.1 mM EDTA, $20 \mathrm{mM} \mathrm{M} \mathrm{gCl} 2,5 \%$ glycerol). KinA was added to a final concentration of $0.5 \mu \mathrm{m}$. The reactions were initiated by the addition of $5 \mu \mathrm{l}$ of a mixture of $\left[\gamma^{32}\right.$ P]ATP and unlabeled ATP to reach a final concentration of $300 \mu \mathrm{m}$. Reactions were carried out for 3 $\mathrm{min}$ at room temperature and stopped by the addition of $12 \mu \mathrm{l}$ of $5 \times$ SDS loading buffer $(25 \mathrm{~mm}$ Tris- $\mathrm{HCl}$ at pH 6.8, 1.5\% SDS, $5 \%$ $\beta$-mercaptoethanol, 10\% glycerol, 0.02\% Bromophenol blue). Reactions were placed in dry ice before loading onto $15 \%$ SDSpolyacrylamide gels. Electrophoresis was carried out at constant voltage (200 V) for $\sim 2.5 \mathrm{hr}$. Where necessary, the lower portion of the gel was removed to reduce the background, which is 
attributable to unincorporated [ $\gamma^{-32}$ P]ATP. Gels were dried and exposed for $1 \mathrm{hr}$ to Kodak AR films.

\section{Purification of KinA P and SpoOF P}

Phosphorylated KinA and SpoOF were purified as follows: $5 \mu \mathrm{M}$ KinA or KinA-C and $25 \mu \mathrm{m}$ SpoOF were labeled by the standard phosphorylation assay in $1 \mathrm{ml}$ volume. After 30 min incubation at room temperature, the mixtures were applied to an FPLC S-100 Sephacryl column $(1.6 \times 64 \mathrm{~cm})$. Gel filtration-purified KinA $\sim P$, KinA $-C \sim P$, and SpoOF P were checked on a 15\% SDSpolyacrylamide gel that had been exposed to autoradiography. KinA-C, spanning from residue 389 to 606, was expressed in the pET 16b expression vector (L. Wang, in prep.). KinA and SpoOF were purified as described previously (Perego et al . 1989; Zapf et al. 1996).

\section{Analytical TLC}

TLC was performed according to Randerath and Randerath (1967), with some modifications. KinA P (30 pmoles) was incubated with $5 \mu \mathrm{M} \mathrm{Kipl} \mathrm{and/or} \mathrm{KipA} \mathrm{in} \mathrm{the} \mathrm{standard} \mathrm{assay} \mathrm{buffer}$ for $5 \mathrm{~min}$ at room temperature. ADP at $300 \mu \mathrm{m}$ final concentration was added to initiate the reactions. Two microliters of stop buffer ( $5 \times$ loading buffer) was added after 3 min incubation, and $1 \mu \mathrm{l}$ from each reaction was applied to PEI cellulose $\mathrm{F}$ layer plates (Alltech). Plates were devel oped in $1.6 \mathrm{M} \mathrm{LiCl}$ for $\sim 45 \mathrm{~min}$ and then dried and exposed overnight to X-ray films. Reactions were al so loaded on $15 \%$ SDS-polyacrylamide gels and exposed to X-ray films as well.

\section{Acknowledgments}

This research was supported in part by grant GM 19416 from the $\mathrm{N}$ ational Institute of General M edical Sciences (N ational Institutes of Health, U.S. Public Health Service). L.W. and R.G. contributed equally to this work.

The publication costs of this article were defrayed in part by payment of page charges. This article must therefore be hereby marked "advertisement" in accordance with 18 USC section 1734 solely to indicate this fact.

\section{References}

Akagawa, E., K. Kurita, T. Sugawara, K. N akamura, Y. Kasahara, N. Ogasawara, and K. Yamane. 1995. Determination of a $17484 \mathrm{bp}$ nucleotide sequence around the $39^{\circ}$ region of the Bacillus subtilis chromosome and similarity analysis of the products of putative ORFs. Microbiology 141: 3241-3245.

Anagnostopoulos, C. and J. Spizizen. 1961. Requirements for transformation in Bacillus subtilis. J. Bacteriol. 81: 741-746.

Arantes, O. and D. Lereclus. 1991. Construction of cloning vectors for Bacillus thuringiensis. Gene 108: 115-119.

Burbulys, D., K.A. Trach, and J.A. Hoch. 1991. The initiation of sporulation in Bacillus subtilis is controlled by a multicomponent phosphorelay. Cell 64: 545-552.

Cunnigham, T.S., R.A. Dorrington, and T.G. Cooper. 1994. The U GA 4 U AS $S_{N T R}$ site required for GLN 3-dependent transcriptional activation also mediates DAL80-responsive regulation and DAL80 protein binding in Saccharomyces cerevisiae. J. Bacteriol. 176: 4718-4725.

Ferson, A.E., L.V. Wray, and S.H. Fisher. 1996. Expression of the Bacillus subtilis gabP gene is regulated independently in repsonse to nitrogen and amino acid availability. Mol. Microbiol. 22: 693-701.
Fleischmann, R.D., M.D. Adams, O. White, R.A. Clayton, E.F. Kirkness, A.R. Kerlavage, C.J. Bult, J. Tomb, B.A. Dougherty, J.M. Merrick et al. 1995. Whole-genome random sequencing and assembly of Haemophilus influenzae Rd. Science 269: 496-512.

Genbauffe, F.S. and T.G. Cooper. 1991. The urea amidolyase (DUR1,2) gene of Saccharomyces cerevisiae. J. DNA Seq. Map. 2: 19-32.

Hoch, J.A. 1993. Regulation of the phosphorelay and the initiation of sporulation in Bacillus subtilis. Annu. Rev. Microbiol. 47: 441-465.

Hoshino, T., K. Kose, and Y. U ratani. 1990. Cloning and nucleotide sequence of the gene braB coding for the sodium-coupled branched-chain amino acid carrier in Pseudomonas aeruginosa PAO. Mol. \& Gen. Genet. 220: 461-467.

Magasanik, B. 1992. Regulation of nitrogen utilization. In The molecular and cellular biology of the yeast Saccharomyces cerevisiae: Metabolism and gene expression (ed. Stratherm et al.), pp. 283-317. Cold Spring Harbor Laboratory Press, Cold Spring Harbor, NY.

Miller, J.H. 1972. Experiments in molecular genetics, pp. 352355. Cold Spring Harbor Laboratory, Cold Spring Harbor, NY.

Ninfa, A.J. and B. Magasanik. 1986. Covalent modification of the glnG product, NRI, by the gInL product, NRII, regulates the transcription of the glnALG operon in Escherichia coli. Proc. Natl. Acad. Sci. 83: 5909-5913.

Ninfa, A.J., M.R. Atkinson, E.S. Kamberov, J. Feng, and E.G. $\mathrm{N}$ infa. 1995. Two-component signal transduction. In Control of nitrogen assimilation by the $N R_{1}-N R_{11}$ two-component system of enteric bacteria (ed. J.A. Hoch and T.J. Silhavy), pp. 67-88. ASM Press, Washington, D.C.

Ohlsen, K.L., J.K. Grimsley, and J.A. Hoch. 1994. Deactivation of the sporulation transcription factor Spo0A by the Spo0E protein phosphatase. Proc. Natl. Acad. Sci. 91: 1756-1760.

Parkinson, J.S. and E.C. Kofoid. 1992. Communication modules in bacterial signaling proteins. Annu. Rev. Genet. 26: 71112.

Perego, M. 1993. Bacillus subtilis and other Gram-positive bacteria: Biochemistry, physiology, and molecular genetics. In Integrational vectors for genetic manipulation in Bacillus subtilis (ed. A.L. Sonenshein, J.A. Hoch, and R. Losick), pp. 615-624. American Society for Microbiology, Washington, D.C.

Perego, M. and J.A. Hoch. 1996a. Cell-cell communication regulates the effects of protein aspartate phosphatases on the phosphorelay controlling development in Bacillus subtilis. Proc. Natl. Acad. Sci. 93: 1549-1553.

- - . 1996b. Protein aspartate phosphatases control the output of two-component signal transduction systems. Trends Genet. 12: 97-101.

Perego, M., S.P. Cole, D. Burbulys, K.A. Trach, and J.A. Hoch. 1989. Characterization of the gene for a protein kinase which phosphorylates the sporulation-regulatory proteins Spo0A and SpoOF of Bacillus subtilis. J. Bacteriol. 171: 6187-6196.

Perego, M., C.G. Hanstein, K.M. Welsh, T. Djavakhishvili, P. Glaser, and J.A. Hoch. 1994. Multiple protein aspartate phosphatases provide a mechanism for the integration of diverse signals in the control of development in Bacillus subtilis. Cell 79: 1047-1055.

Perego, M., P. Glaser, and J.A. Hoch. 1996. Aspartyl-phosphate phosphatases deactivate the response regulator components of the sporulation signal transduction system in Bacillus subtilis. Mol. Microbiol. 19: 1151-1157.

Posas, F., S.M. Wurgler-M urphy, T. M aeda, E.A. Witten, T.C. Thai, and J. Saito. 1996. Y east HOG1 MAP kinase cascade is 
regulated by a multistep phosphorelay mechanism in the SLN 1-YPD1-SSK1 "two-component" osmosensor. Cell 86: 865-875.

Randerath, K. and E. Randerath. 1967. Thin-layer separation methods for nucleic acid derivatives. Methods Enzymol. 12: 323-347.

Richardson, I.B., M.E. Katz, and M.J. Hynes. 1992. Molecular characterization of the lam locus and sequences involved in regulation by the AmdR protein of Aspergillus nidulans. Mol. Cell. Biol. 12: 337-346.

Schaeffer, P., J. Millet, and J. Aubert. 1965. Catabolic repression of bacterial sporulation. Proc. Natl. Acad. Sci. 54: 701-711.

Spizizen, J. 1958. Transformation of biochemically deficient strains of Bacillus subtilis by deoxyribonucleate. Proc. Natl. Acad. Sci. 44: 1072-1075.

Trach, K.A. and J.A. Hoch. 1993. Multisensory activation of the phosphorelay initiating sporulation in Bacillus subtilis: Identification and sequence of the protein kinase of the alternate pathway. Mol. Microbiol. 8: 69-79.

Uhl, M.A. and J.F. Miller. 1996. Integration of multiple domains in a two-component sensor protein: The Bordetella pertussis BvgAS phosphorelay. EMBO J. 15: 1028-1036.

Whitney, P.A. and T.G. Cooper. 1973. Urea Carboxylase from Saccharomyces cerevisiae. J. Biol. Chem. 248: 325-330.

Wray, L.V., A.E. Ferson, K. Rohrer, and S.H. Fisher. 1996. TnrA, a transcription factor required for gl obal nitrogen regulation in Bacillus subtilis. Proc. Natl. Acad. Sci. 93: 8841-8845.

Zapf, J.W., J.A. Hoch, and J.M. Whiteley. 1996. A novel phosphorylation activity of the Bacillus subtilis sporulation protein SpoOF that employs phosphorami date substrates. J. Biol. Chem. 35: 2926-2933. 


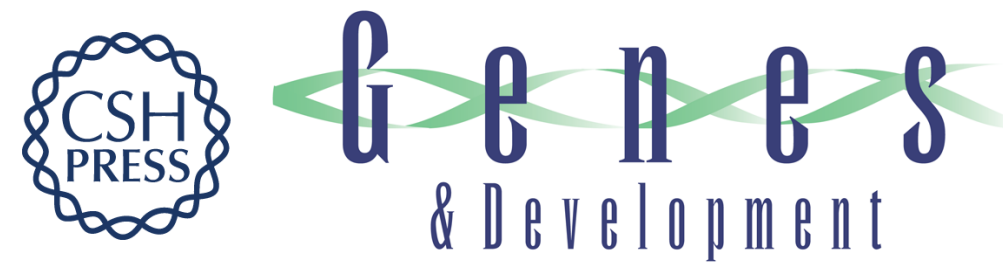

\section{A novel histidine kinase inhibitor regulating development in Bacillus subtilis}

Ling Wang, Roberto Grau, Marta Perego, et al.

Genes Dev. 1997, 11:

Access the most recent version at doi:10.1101/gad.11.19.2569

References

This article cites 27 articles, 11 of which can be accessed free at: http://genesdev.cshlp.org/content/11/19/2569.full.html\#ref-list-1

License

Email Alerting

Receive free email alerts when new articles cite this article - sign up in the box at the top Service right corner of the article or click here.

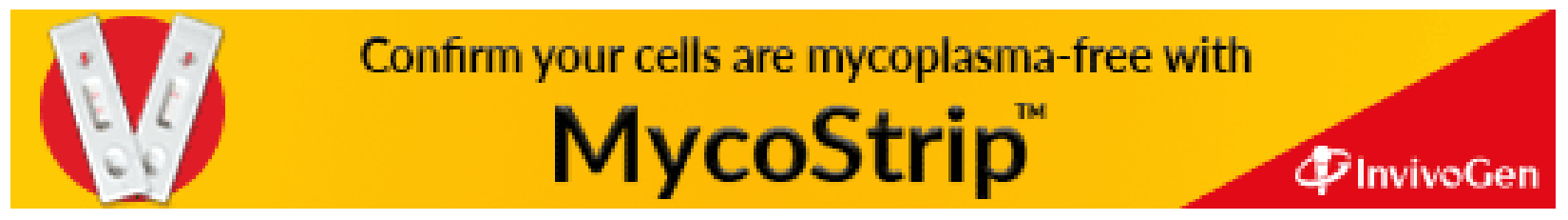

